\title{
Application and Teaching Implication of Discourse Analysis in Reading Comprehension
}

\author{
Yonghong $\mathrm{Wu}$ \\ Xi'an University, School of Foreign Studies, 710065
}

Keywords: Reading comprehension, Discourse analysis, Application and teaching implication

\begin{abstract}
In the field of foreign language education, reading comprehension has long been proven to be the most important among the five skills of listening, speaking, reading, writing and translating. Therefore, to enhance foreign language learners' reading comprehension is, to a great extent, to enhance their ability of using all the five skills they have learnt in learning a foreign language. The writer of this paper attempts to put discourse analysis approach into the teaching practice of reading comprehension to enable English learners to get into a good habit of reading and improve the teaching efficiency of reading.

A great number of foreign language teachers and researchers have done lots of research work on the functions of reading motivation, reading speed and cultural factors in foreign language reading comprehension, and others' research involves reading materials, reading skills and reading testing. All these scholars' newly findings have positively, to some extent, improved readers' abilities. The writer of this paper attempts to put this approach into the teaching practice of reading comprehension. By comparing the modes of foreign language reading comprehension and problems existing in this field with discourse analysis approach, the writer thinks that using this method is not only beneficial to language communication but helpful to reach a profound comprehension of language as well, and using this method enables us to give new definitions to some common language phenomena. Especially for those beginners, using discourse analysis approach can make them understand the text at a glance of the text structures, text themes and the writers' ideas. Moreover, using such an approach can benefit our teaching a lot. In this way, our readers can foster a logical thinking ability of analyzing, summarizing and inducing, and also our readers can get twice the result with half the effort in foreign language reading.
\end{abstract}

\section{Reading Comprehension}

Linguists and psychologists have proposed different descriptions and definitions to reading comprehension. Bloomfield, Fries, and some other linguists had some similar opinions. They thought reading is to identify language units from the simple to the complex; reading is a simple and mechanical process of decoding ( Kavanagh \& Mattingly, 1972 ). But, modern linguists and psychologists have different opinions on this problem. They deepened their research on reading comprehension and gave it more proper explanations with the help of the development of contemporary linguistics and cognitive science. For modern linguists and psychologists, reader is an active individual who can make a choice and determination. At the same time, our reader can make the process of understanding go ahead smoothly by various means and techniques. ( Silberstein,1987 ) We cannot avoid visual activities when we are reading, and we can only put the literary signals into our brains with our eyes, but scientific research has discovered that such a visual activity is not like what we think it is----we only identify the written forms one by one. On the contrary, when we are reading, we receive a group of lirerary signals and proceed quickly, which some people called 'CHUNKING'( Dubin \& others, 1986 ). Furthermore, our brains participate in this process actively; hence, we call reading comprehension a cognitive process. In all, reading comprehension is a complicated cognitive process. ( Ma Zhuanghuan, 2002 ) In order to deepen their research on reading comprehension, psycholinguists described reading process as three modes according to their research and observation. 


\section{Reading Comprehension Modes}

Bottom-up ( micro ) Processing: 'Bottom-up 'process supposed that readers firstly have literary information in mind when they transfer these signals to semantic information, namely, reading process is one of identification from the simple units, such as alphabets, words and sentences to more complex language units.

Top-down ( macro ) Processing: The 'top-down' process followers thought that reading mainly depended on the pre-existent knowledge in readers' minds, including linguistic and non-linguistic factors. Reading process starts from the readers' inference and anticipation of the text. ( Vacca et al, 1987 ) So, this mode was also called a knowledge-based one. ( Silberstein, 1987 ) Goodman had ever made such a brilliant exposition, 'Reading is a process of choosing, which mainly depends on the readers' expectations and partially take advantage of the least language information from our visual input; then the temporary decisions will be confirmed, rectified, or eliminated with the development of the reading process. Suffice it to say here that reading is a psycho-linguistic RIDDLE GAME.' ( Dubin and others, 1986 ) Smith also said that 'those our minds tell to our eyes' were much more important than 'those our eyes tell to our minds'. ( Dubin and others, 1986 )

Interactive Processing: 'Interactive' refers to the inter-functions occurred between the text and the reader----also between the visual information and the pre-existent knowledge, namely, a combination of the above two modes. 'Interactive' process discovered that the meaning of a text is not self-evident but is created by the reader and the text together. Besides, the interactive process described reading a two-way one, once which stops or is replaced by a one-way process, our reading comprehension will be hindered.

2. Problems Existing in Reading Comprehension

Overstressing the input of visual information at the expense of ignoring the function of the pre-existent knowledge in readers' minds: reading comprehension is a two-way process, and it needs readers' cooperation with the text. From the discourse linguistics perspective, any text has a redundancy phenomenon, which is just ignored by reading in a straight forward way, so it is not scientific. An efficient reader is good at grasping the focal points and a large quantity of semantic or conceptual information from the least visual input.

Failing to see the wood for the trees, then holding up the transmission of the semantic information: our main target of using language of communication is to deliver semantic content and pragmatic information, and in written language the former often plays a dominant part.(Van Dijk and Kintsch, 1983)From modern linguistics perspective, semantic meaning does not exist in language spontaneously but is created by discourse deliverer and receiver, and we also know that it is the entirety rather than the individual words or sentences that has a communicative function. Besides, readers are always expecting to understand a text by making use of the language clues provided by the text and the pre-existent knowledge so that they can reach their aim of communication. If our readers are too concentrated on the details to ignore the whole text, they will not get the expected semantic content, and they will lose their cooperation with the discourse deliverer. Then, the reading process will not be continued because the reading objective is destroyed and reading itself becomes meaningless.

Being immersed in part of a text, which is slow in speed and does no help to memory process then destroys reading comprehension: psychologists discovered that there were the following three memory types: the sensory store, the short-term memory, and the long-term memory. Besides, their memory played an absolutely important role. The short-term memory can only store four or five information units, which is rather limited. Therefore, our readers should enlarge the information capacity to promote the efficiency of this process. That is to say, readers should not view from the angle of individual words or expressions other than more complex units 'CHUNKING' mentioned above.

Our reading objective is to understand various texts. So, from the discourse analysis perspective, the writer of this paper wants to introduce the discourse analysis approach and provide some practical discourse analysis skills to share with the readers and solve the problems existing in foreign language reading comprehension. 


\section{Discourse Analysis}

1. Text linguistics

With the development of modern linguistics, its scope has been constantly broadened, which has experienced an up-ward and down-ward process of development from syllables to words then to texts. So, text linguistics was put forward. Text linguistics is a new discipline sprang up aboard in the past 30 years, and it is an important branch of linguistics. Halliday's functional linguistics attached much importance to social functions and meta-functions of language (Huang Guowen, 2001); Labov (1972) gave language variables an unparalleled research. At home, though text linguistics has only developed for twenty years, it has obtained remarkable achievements, and scholars such as, Hu Zhuanglin, Xu Shenghuan, Fang Yan, Huang Guowen, Zhu Yongsheng etc. have achieved remarkable results. The objective of text linguistics is to analyze different types of texts. Some text linguists regard text as a 'SUPERSENTENCE' that is more complex but with the same quality like a sentence. Therefore, they also call text linguistics 'TEXT GRAMMAR'. Systemic-functional grammar looks text as a meaning unit rather than a 'SUPERSENTENCE', and text is a realistic example of human communication.

2. Discourse Analysis Types and Approaches

Generally speaking, there are two kinds of discourse analysis. One is macrostructure research, which looks text as a whole unit and is mainly studies the structures or the organizations of the text, and the other is microstructure research, which mainly studies inter-sentence relationship, identify the relation signals among sentences and studies how series of sentences construct a coherent text.

Though text linguistics has developed a lot, at present, there is no fixed or standard discourse analysis approaches. The writer of this paper mainly wants to list the following ones: speech acts theory approach, pragmatics approach, interactive social linguistics approach, conversational analysis approach, and communicative cultural approach. Even to analyze the internal structures of a text, there are lots of methods. The following factors cause difficulty in discourse analysis: Sentence structures; Cohesive means; Discourse signs and Cultural backgrounds.

From the above analysis, we have drawn the conclusion that reading comprehension is an interactive process of the bottom-up process and the top-down process, that is also an interactive process of the literary information input and the pre-existent knowledge in readers' minds. In short, it is a combined, complicated, and cognitive process of micro-process and macro-process. Then we have introduced two categories of discourse analysis, microstructure research and macrostructure research, which, to some extent, just tally with the reading comprehension process. Besides this, discourse analysis approach involves some other disciplines such as grammar, pragmatics, semantics, and so forth. The writer of this paper is willing to provide some practical discourse analysis skills from three aspects to share with our readers.

\section{Application and Teaching Implication}

Based upon the analysis above, discourse analysis can be applied in reading teaching from the following aspects:

1. Sentence Analysis:

Readers know all the words in a sentence but they cannot understand the whole sentence, which is because the sentence is too long or the sentence structures are too complicated. Under such a circumstance, our readers should practice analyzing sentences. Firstly, read a text quickly and try to get the relevant information as much as possible. Secondly, read the text slowly and try to look up some vital words in the dictionary to make them clear. Thirdly, raise some questions that the text is likely to give answers. Fourthly, read the text once more so that you can find some evidence that can prove your answers are correct. Till now, our readers will understand most of the sentences and have a general impression of the main idea of the text. If our readers are still at a loss about some sentences that stop their further reading, they should learn how to analyze sentences.

2. Cohesive means analysis:

We will mainly talk about how to identify and understand some factors, cohesive means, 
which do good to readers' reading comprehension. Halliday and Hasan(1976) had elaborately talked about the problem of inter-sentence coherence. However, we might meet reading difficulty because of coherent factors. Cohesive means mainly include five types: Reference, Ellipsis, Substitution, Conjunction, Lexical cohesion ( Hu Zhuanglin, Zhu Yongsheng, Zhang Delu, 1989). Here, we mainly analyze this problem from the following aspects:

1.) Identifying and understanding reference and substitution, which refers to how to identify and understand the words such as it, he, our, this, those, then, one(as in the wrong one), so/not(as in I think so, it appears not) and comparatives(smaller, same, additional, such, other, etc.) and what they refer to. Firstly, our readers should attach enough importance to reference and substitution. Secondly, our readers should make good efforts to find out such words and make clear what they refer to and what they substitute. In this way, their speed and efficiency of reading will be improved.

2.) Identifying and understanding ellipsis: In the process of communication, people often omit those they think their readers or listeners can complement according to the context, which is called ellipsis in linguistics. Readers also should find out those information omitted. For students, our teachers should prepare some exercises to practice such a language phenomenon so that the students can find out the omitted parts when they are reading and understand the text more quickly and thoroughly.

3.) Identifying and understanding lexical cohesion: Generally, writers will not use the same words because of different writing styles. They will choose a synonym to replace a used word. Sometimes, they will replace a low-class word with a high-class word(e.g. replacing house with building). And they often substitute the previously used words by metaphors(e.g. replacing house with nest). Under such a circumstance, our readers should not only find out the implications of the metaphors but also understand the previous three aspects, especially the last one.

4.) Identifying and understanding conjunctions: In this part, we will discuss those signal words that guide our readers to make clear the relationship of different parts in a text. These signal word often tell readers the functional values of sentences. From reading comprehension perspective, there are the following three: Events arranged in the order in which they occurred; Methods a writer using to organizing discourse; Writer's opinions.

The first group includes some signal words such as then, first, at once, next, the following day etc. the second group involves the signal words such as in conclusion, that is to say, in this connection, for example, to resume, in short and so on. The third group covers the signal words such as moreover, incidentally, similarly, however, as a matter of fact, in any case, therefore, in order to, if, although and so forth.

5.) Identifying the rhetorical structures: Our readers should firstly make clear the title of the text, the willingness of the writer and the expected readers. After this, they should know how the writer reached his aim, which needs them to study the process of rhetorical development. This process includes contents and types of literature, internal structure of a sentence, inter-sentence structures, inter-paragraph structures etc. Research has testified that the best way is to start from the inter-paragraph structures. Readers firstly study how the individual paragraph form a text, then how the sentences formed a paragraph, and finally the internal structures of an individual sentence. And they can take advantage of a diagram to get a clear idea of the rhetorical structures.

\section{Conclusion}

As a matter of fact, discourse analysis skills are far beyond the three mentioned above because at present there are not standard or fixed discourse analysis approaches or modes. In this paper, by analyzing the process of reading comprehension and introducing discourse analysis approach, the writer of this paper thinks that in reading comprehension, our readers should adopt an interactive way, that is to say, they should analyze a text in a macro-way, and only in this way, can our readers understand a text more quickly and thoroughly, then their language skills will be improved. Things that our teachers should pay attention to are: First, master abundant language knowledge, such as grammar, lexicology, syntax, linguistics, pragmatics and so on; second, set foot in varied 
background knowledge, such as cultures both at home and abroad, literatures, philosophy, psychology, anthropology and things alike. All these knowledge is not only beneficial for readers to develop their discourse analysis skills but also helpful to make reading teaching efficient.

\section{References}

[1] Carrell, p.1. 1983. Schema Theory and Language Comprehension [A]. In J.C.R. Richards, M.H. Long \& R.W. Schmidt. Working Papers. Department of English as a second Language University of Hawaii at Manoa.

[2] Dubin, F. et al. 1986. Teaching Second Language Reading for Axademic Purposes [M]. Massachusetts: Addison-Wesley Publishing Company

[3] Halliday, M.A.D. and Hasan, R. Cohesion in English Longman, 1976.

[4] Hu Zhuanglin, Zhu Yongsheng, Zhang Delu, 1997, The Profile of Systamic Functional Grammar [M]. Hunan: Hunan Education Press.

[5] Huang Guowen, 2001, Functional Grammar Analysis [J]. Foreign Language and Foreign Language Teaching.

[6]Huang Guowen, 2001, The Theory and Practice of Discourse Analysis[M], Shanghai: Shanghai Foreign Language Education Press.

[7] Kvanagh, James F. Mattingly, 1972. Lgnatius G. Language by Ear and Eye[C], the Relationship between Speech and Reading. Cambridge: the MIT Press

[8] Ma Zhuaghuan, 2002, Language Research Papers [C]. Beijing: ZHONGHUA Book Company

[9] Mc Donough, S. 1995. Strategy and Skill in Learning a Foreign Language[M]. Edward Arnold, Britain.

[10] Silberstein, Sandra. 1987. 'Let's Take another Look at Reading: Twenty-Five Years of Reading Instruction', Forum, Volume XXV, Number4.

[11] Vacca, Jo Anne L. Vacca, Richard T. 1987 \& Mary K. Reading and Learning to Read[M]. Boston: Little Brown and Company.

[12] Van Dijk, Teun A. \& Kintsch, Water. 1983. Strategies on Discourse Comprehension[M]. New York: Academic Press. 